\title{
Expression of maternally derived KHDC3, NLRP5, OOEP and TLE6 is associated with oocyte developmental competence in the ovine species
}

Daniela Bebbere*, Federica Ariu, Luisa Bogliolo, Laura Masala, Ombretta Murrone, Mauro Fattorini, Laura Falchi and Sergio Ledda

\begin{abstract}
Background: The sub-cortical maternal complex (SCMC), located in the subcortex of mouse oocytes and preimplantation embryos, is composed of at least four proteins encoded by maternal effect genes: OOEP, NLRP5/ MATER, TLE6 and KHDC3/FILIA. The SCMC assembles during oocyte growth and was seen to be essential for murine zygote progression beyond the first embryonic cell divisions; although roles in chromatin reprogramming and embryonic genome activation were hypothesized, the full range of functions of the complex in preimplantation development remains largely unknown.
\end{abstract}

Results: Here we report the expression of the SCMC genes in ovine oocytes and pre-implantation embryos, describing for the first time its expression in a large mammalian species.

We report sheep-specific patterns of expression and a relationship with the oocyte developmental potential in terms of delayed degradation of maternal SCMC transcripts in pre-implantation embryos derived from developmentally incompetent oocytes.

In addition, by determining OOEP full length cDNA by Rapid Amplification of CDNA Ends (RACE) we identified two different transcript variants (OOEP1 and OOEP2), both expressed in oocytes and early embryos, but with different somatic tissue distributions.

In silico translation showed that 140 aminoacid peptide OOEP1 shares an identity with orthologous proteins ranging from $95 \%$ with the bovine to $45 \%$ with mouse. Conversely, OOEP2 contains a premature termination codon, thus representing an alternative noncoding transcript and supporting the existence of aberrant splicing during ovine oogenesis.

Conclusions: These findings confirm the existence of the SCMC in sheep and its key role for the oocyte developmental potential, deepening our understanding on the molecular differences underlying cytoplasmic vs nuclear maturation of the oocytes.

Describing differences and overlaps in transcriptome composition between model organisms advance our comprehension of the diversity/uniformity between mammalian species during early embryonic development and provide information on genes that play important regulatory roles in fertility in nonmurine models, including the human.

Keywords: Ovine embryo, Oocyte developmental competence, Subcortical Maternal Complex

\footnotetext{
* Correspondence: dbebbere@uniss.it

Department of Veterinary Medicine, University of Sassari, via Vienna 2, 07100

Sassari, Italy
} 


\section{Background}

The subcortical maternal complex (SCMC) is a multiprotein complex located in the sub-cortex of mouse oocytes and pre-implantation embryos [1] composed by at least four proteins: Oocyte Expressed Protein [(OOEP) also known as Factor Located in Oocytes Permitting Embryonic Development (FLOPED)], NLR family, pyrin domain containing 5 [(NLRP5) also known as Maternal Antigen That Embryo Requires (MATER)], TransducinLike Enhancer of Split 6 (TLE6) and KH domaincontaining protein 3 [(KHDC3), also known as FILIA)]. The SCMC was seen to be essential for murine zygote progression beyond the first embryonic cell divisions [1], however little is known about the complex in species other than mouse.

The proteins that contribute to the SCMC are encoded by maternal effect genes (MEGs; [1-4]). MEGs code for a special class of maternal transcripts necessarily required for the early cleavage events post fertilization $[5,6]$. They are expressed exclusively in oocytes and early embryos and are usually degraded by the time of embryonic genome activation (EGA), without compensation by embryonic transcription. Functional studies in mice have indeed demonstrated that the knockout of MEGs results in the inability of the embryo to develop beyond the first cleavage stage [2,7]. This was observed also in Nlrp5, Ooep and Khdc3 case: the lack of either gene in mouse oocytes does not affect folliculogenesis, ovulation, or fertilization, but leads to the failure of early embryos to complete cleavage stage development, resulting in a striking female sterile phenotype in these mutant mice $[1,2,4,8]$. MEGs are involved in folliculogenesis, fertilization and pre-implantation embryo development [5], however their specific functions are often unclear, as in SCMC case.

The molecular mechanisms contributing to oogenesis and to early embryo development are highly conserved. In mammals, maternally-deposited transcripts were seen to be generally more conserved than the newly synthesized by the nascent embryo [9]; comparative genomics studies between mammals and phylogenetically distant chordates such as X. laevis and sea squirt Ciona intestinalis highlighted the conservation of the majority of the genes expressed in the oocytes [10-12].

Nevertheless, inherent species-specific differences, such as the ovulation quota and number of embryonic cell cycles required for EGA [13], exist between the traditional animal model (polyovulatory mouse) versus monoovulatory species, such as large domestic animals and primates, including humans. Numerous examples suggest that oocyte specific genes may not have identical functions in different species [14-19]. This is possibly related to the fact that several genes specifically expressed by the oocyte are organized in clusters and subject to rapid molecular diversification, often via gene duplication mechanisms
[10,20-22]; this was seen to happen more often for genes that play a role in reproduction processes [23].

The picture of the oocyte transcriptome reveals a delicate balance between novelty and conservation. Comparative studies in nontraditional model systems are valuable to address dissimilarities and overlaps in transcriptome composition between model organisms, and provide information on genes that may play important regulatory roles in fertility in nonmurine models, including the human.

The SCMC appears to be an interesting combination between conservation and novelty: while NLRP5/MATER is conserved in several mammalian species, with a moderate grade of sequence homology [2,24-26], OOEP e KHDC3 belong to an eutherian oocyte and embryoexpressed gene family subject to rapid molecular diversifications [27], whose expression analysis in oocytes and embryos of species other than mouse is still lacking.

In light of the above, the goal of the present study was to analyse the expression of the MEGs encoding the SCMC in the ovine species. We have previously studied the expression of NLRP5 in sheep oocytes and embryos [24]. In the present work, OOEP, KHDCL3 and TLE6 existence was assessed, and the expression pattern during in vitro oocyte maturation and embryo development was analysed, together with the potential expression in somatic tissues. A possible association between the expression of the SCMC four components and the oocyte developmental ability was assessed in a model of differential competence consisting of oocytes derived from adult (Ad) or prepubertal (Pr) donors.

Finally, the full length cDNA of OOEP was determined by Rapid Amplification of cDNA Ends (RACE).

\section{Methods}

All chemicals in this study were purchased from Sigma Chemical CO. (St. Louis, MO, USA) unless otherwise stated.

All experiments involving animals were performed in accordance with the relevant guidelines for the care and use of animals. No animals were specifically generated or sacrificed for this study. Samples were obtained from animals regularly slaughtered in local abattoirs for food production purposes. All procedures were approved by the ethics committee of the University of Sassari, Italy.

\section{Oocyte recovery and in vitro maturation}

Oocytes were recovered from the ovaries of prepubertal (30-40 days of age, body weight $6-10 \mathrm{~kg}$ ) and adult (4-5 years of age, body weight $35-40 \mathrm{~kg}$ ) Sarda sheep collected at a local slaughterhouse and transported to the laboratory within $1 \mathrm{hr}$ in Dulbecco's phosphate buffered saline (PBS) with antibiotics. After washing in fresh medium, ovaries were sliced using a micro-blade and the follicle content was released in TC-199 medium (with Earle's salts and 
bicarbonate) supplemented with 25 mmol HEPES, $0.1 \mathrm{~g} / \mathrm{L}$ penicillin, $0.1 \mathrm{~g} / \mathrm{L}$ streptomycin, and $0.1 \%(\mathrm{w} / \mathrm{v})$ polyvinyl alcohol.

The cumulus oocyte complexes (COCs) showing several intact cumulus cell layers and a compact cytoplasm were selected and matured in vitro in TCM 199 supplemented with $10 \%$ heat treated oestrus sheep serum (OSS), $0.1 \mathrm{IU} / \mathrm{ml} \mathrm{FSH}$ and $0.1 \mathrm{IU} / \mathrm{ml} \mathrm{LH}$ (Pergonal, Serono Italy) and $100 \mu \mathrm{M}$ cysteamine. Groups of 30-35 COCs were cultured for $24 \mathrm{~h}$ in a humidified atmosphere of $5 \% \mathrm{CO}_{2}$ in air at $38.5^{\circ} \mathrm{C}$ in four-well Petri dishes (Nunclon; Nalge Nunc, Roskilde, Denmark) with $600 \mu \mathrm{L}$ maturation medium, layered with $300 \mu \mathrm{L}$ mineral oil.

\section{In vitro fertilization and embryo development}

Frozen-thawed spermatozoa of one single ram of proven fertility (Sarda breed, 4 years old, body weight 55$60 \mathrm{~kg}$ ), selected by the swim-up technique, were used for all in vitro embryo production experiments. Two straws were thawed per IVF. The semen was washed twice with SOF medium with $2 \%(\mathrm{v} / \mathrm{v})$ OSS for 20 minutes. Finally, sperm pellet $\left(1 \times 10^{6}\right.$ spermatozoa $\left.\mathrm{mL}^{-1}\right)$ and IVM oocytes were incubated in fertilization medium [Synthetic Oviductal Fluid (SOF) medium with $2 \%$ OSS, $1 \mu \mathrm{g} / \mathrm{mL}$ heparin and $1 \mu \mathrm{g} / \mathrm{mL}$ hypotaurine] for $22 \mathrm{~h}$ at $38.5^{\circ} \mathrm{C}$ in an atmosphere of $5 \% \mathrm{CO}_{2}$ and $5 \% \mathrm{O}_{2}$ in $\mathrm{N}_{2}$ in four-well Petri dishes (Nunclon) [28].

Thereafter, presumptive zygotes were transferred and cultured for 8 days in four-well Petri dishes containing $\mathrm{SOF}+$ essential and non-essential amino acids at oviductal concentrations [29] $+0.4 \%$ bovine serum albumin (BSA) under mineral oil, in a maximum humidified atmosphere with $5 \% \mathrm{CO}_{2}, 5 \% \mathrm{O}_{2}$ and $90 \% \mathrm{~N}_{2}$ at $38.5^{\circ} \mathrm{C}$ [30]. The first cleavage was recorded between 24 and $26 \mathrm{~h}$ after fertilization.

\section{Gene expression analysis}

Oocyte and embryo collection for gene expression analysis

The RNA samples were isolated from pools of denuded germinal vesicles (GV) and IVM metaphase II (MII) oocytes, and from pools of in vitro matured, fertilized and cultured (IVMFC) embryos at the two- (2C), four- (4C), eight- (8C), and 16-cell (16C) stage. Oocytes and embryos were obtained during several IVM, IVF and IVC sessions.

For a proper collection of oocytes, the assessment of nuclear maturation (GV or MII) was performed by visualization with a stereomicroscope (Olympus ZX40) at $40 \mathrm{X}$ magnification. Although the assessment of the meiotic stage cannot be performed with an absolute confidence in absence of staining, according to our experience, ovine oocytes soon after follicular collection are prevalently at the GV stage (98\%), while they reach the MII stage and show the presence of the polar body after $24 \mathrm{~h}$ of in vitro culture. Oocytes at the GV and MII stages were denuded with a fine narrow bore pipette and defined as good quality when showing uniform cytoplasm.

Samples were analysed in pools, where every single pool contained 10 oocytes or 10 embryos, in order to obtain enough RNA for the analysis of the 7 transcripts. Five pools were analysed for GV ( $\mathrm{n}=5$ pools) and MII $(\mathrm{n}=5$ pools) oocytes, while three pools were analysed for embryos at all developmental stages. Each pool was added to $2 \mu \mathrm{l}$ RNase free water, snap frozen in liquid nitrogen, and stored at $-80^{\circ} \mathrm{C}$ until RNA isolation.

The same sampling was performed for oocytes and embryos derived from adult (Ad) and from prepubertal donors (Pr).

As a control for IVF procedure, a pool of embryos in each IVF run was cultured until the blastocyst stage to assess the developmental competence of the fertilized eggs. Only embryos collected from controlled experiments with rates of development to blastocyst stage of $>25 \%$ (day 7) were used in the analysis.

Ten single blastocysts derived from Ad $(\mathrm{n}=5)$ and $\mathrm{Pr}$ $(n=5)$ oocytes were analysed in order to assess the presence of the transcripts after the activation of the embryo genome.

\section{RNA Isolation and reverse transcription}

Total RNA was isolated from the groups of oocytes or embryos with the RNeasy Micro Kit (Qiagen, Hilden, Germany) following manufacturer's instructions. Five pg of luciferase mRNA (Promega) were added to each group prior to RNA extraction to account for RNA loss during the isolation process.

During the procedure, RNA was treated with DNase I to exclude any potential genomic DNA contamination. Isolated RNA was eluted in $15 \mu \mathrm{L}$ RNase-free water and $13.5 \mu \mathrm{L}$ immediately used for reverse transcriptionpolymerase chain reaction (RT-PCR).

One point five $\mu \mathrm{L}$ RNA was analysed with Agilent 2100 Bioanalyzer (Agilent Technologies) with an RNA 6000 Pico kit (Agilent Technologies), specifically designed for analysis of low concentrated RNA samples (analysis range of total RNA: $50-5000 \mathrm{pg} / \mu \mathrm{l}$ ).

Reverse-transcription was performed in a final volume of $20 \mu \mathrm{L}$, consisting of $50 \mathrm{mM}$ Tris $-\mathrm{HCl}(\mathrm{pH} 8.3)$, $75 \mathrm{mM} \mathrm{KCl}, 3 \mathrm{mM} \mathrm{MgCl}$, $5 \mathrm{mM}$ DTT, $1 \mathrm{mM}$ dNTPs, $2.5 \mu \mathrm{M}$ random hexamer primers, $0.05 \mu \mathrm{g}$ oligo $(\mathrm{dT})_{18}$ primers, $20 \mathrm{U}$ RNase OUT and $100 \mathrm{U}$ SuperScript III RT (all purchased at Invitrogen Corporation, Carlsbad, $\mathrm{CA})$. The reaction tubes were incubated at $25^{\circ} \mathrm{C}$ for $10 \mathrm{~min}$, then at $42^{\circ} \mathrm{C}$ for $1 \mathrm{~h}$ and finally at $70^{\circ} \mathrm{C}$ for $15 \mathrm{~min}$ to inactivate the reaction. One tube without RNA and one with RNA, but without reverse transcriptase, were analysed as negative controls. To quantify the mRNA recovery rate, $5 \mathrm{pg}$ of luciferase mRNA (not 
subjected to RNA isolation) were subjected to cDNA synthesis as well.

\section{Real time-polymerase chain reaction}

Primers for all genes studied are listed in Table 1. Relative quantification of transcripts was performed by realtime polymerase chain reaction (RT-PCR) in a 7900HT Fast Real-Time PCR System (Applied Biosystems). The PCR was performed in a $15 \mu \mathrm{L}$ reaction volume containing $7.5 \mu \mathrm{L} 2 \times$ SYBR Green PCR Master Mix (Applied Biosystems, Foster City, CA), 200 nM of each primer and $\mathrm{CDNA}$ equivalent to 0.25 oocytes or embryos.

The PCR protocol consisted in two incubation steps $\left(50^{\circ} \mathrm{C}\right.$ for $5 \mathrm{~min}$ and $95^{\circ} \mathrm{C}$ for $2 \mathrm{~min}$ ), followed by $40 \mathrm{cy}$ cles of amplification program $\left[95^{\circ} \mathrm{C}\right.$ for $15 \mathrm{~s}$, genespecific annealing temperature (see Table 1) for $30 \mathrm{~s}$ and $72^{\circ} \mathrm{C}$ for $30 \mathrm{~s}$, a melting curve program $\left(65-95^{\circ} \mathrm{C}\right.$, starting fluorescence acquisition at $65^{\circ} \mathrm{C}$ and taking measurements at 10 -s intervals until the temperature reached $95^{\circ} \mathrm{C}$ ) and finally a cooling step to $4^{\circ} \mathrm{C}$. Fluorescence data were acquired during the $72^{\circ} \mathrm{C}$ extension steps.

To minimise handling variation, all samples to be compared were run on the same plate using a PCR master mix containing all reaction components apart from the sample.

The PCR products were analysed by generating a melting curve to check the specificity and identity of the amplification product. For each primer pair, the efficiency of the PCR reaction was determined by building a standard curve with serial dilutions of a known amount of template, covering at least 3 orders of magnitude, so that the calibration curve's linear interval included the interval above and below the abundance of the targets. Only primers achieving an efficiency of reaction between
90 and $110 \%$ (3.6 > slope >3.1) and a coefficient of determination $r^{2}>0.99$ were used for the analysis.

The sizes of the RT-PCR products were further confirmed by gel electrophoresis on a $2 \%$ agarose gel stained with Sybr Safe (Invitrogen) and visualised by exposure to blue light. The PCR products were sequenced (Model 3130 xl Genetic Analyzer; Applied Biosystems, Foster City, CA, USA) after purification with MinElute PCR purification kit (Qiagen) and sequence identities were confirmed with BLAST (http://www.ncbi.nlm.nih.gov/ BLAST/). The relative quantification of the SCMC transcripts was performed after normalization to the number of oocytes and embryos [31-33]. Real-time RT-PCR data are presented as $\Delta \mathrm{Cq}$, mean $\pm \mathrm{SEM}$. The relative amount of the target mRNA of each specific sample was obtained after subtraction of the calibrator expression level $(\Delta \mathrm{CT}$ sample $=\mathrm{CT}$ sample $-\mathrm{CT}$ calibrator), where the calibrator was the sample showing the highest abundance (in most cases a pool of oocytes at the GV stage).

\section{Tissue collection, RNA isolation and reverse transcription}

Ovine tissue samples including adult lung, muscle, kidney, cerebellum, testis, ovary, spleen, liver and heart were collected at a local slaughterhouse. All samples were immediately plunged into RNALater (Qiagen, Hilden, Germany) and stored at $-80^{\circ} \mathrm{C}$ until RNA isolation. Total RNA was isolated using TRIzol reagent (Invitrogen, Carlsbad, CA) and treated with DNase I (Invitrogen, Carlsbad, CA) according to manufacturer's protocols. Resulting RNA quantity and purity was spectroscopically checked with NanoDropLite (Fisher Scientific S.A.S., France).

Five hundred ng total RNA from each different tissue were reverse transcribed in a $20 \mu \mathrm{L}$ reaction with $50 \mathrm{mM}$ Tris $\mathrm{HCl}$ (pH 8.3), $75 \mathrm{mM} \mathrm{KCl,} 3 \mathrm{mM} \mathrm{MgCl}_{2}$,

Table 1 Primers used for real-time PCR experiments

\begin{tabular}{|c|c|c|c|c|}
\hline Gene & GenBank accession $\mathbf{n}$. & Primers & Annealing temperature & Size (bps) \\
\hline \multirow[t]{2}{*}{ KHDC3 } & XM_004011872 & F: 5' CAGACCCTGCTTCACGTTCA 3' & $60^{\circ} \mathrm{C}$ & 150 \\
\hline & & R: 5' CTTCTCAGAGCTTCGCGCC 3' & & \\
\hline \multirow[t]{2}{*}{ NLRP5 } & HM037368.1 & F: 5' CAGCCTCCAGGAGTTCTTTG 3' & $59^{\circ} \mathrm{C}$ & 212 \\
\hline & & R: 5' GACAGCCTAGGAGGGTTTCC 3' & & \\
\hline \multirow[t]{2}{*}{ OOEP 1} & KF218578 & F: 5' ATCCGCTGGTGTTCTTCCTG 3' & $60^{\circ} \mathrm{C}$ & 149 \\
\hline & & R: 5' GAACACGGTGACTTCGACCA 3' & & \\
\hline \multirow[t]{2}{*}{ OOEP 2} & KF741040 & F: 5' TCCCCAAACTCCTTGCAGTG 3' & $60^{\circ} \mathrm{C}$ & 114 \\
\hline & & R: 5' CGGCAGGTAGGTGTCTGAAT 3' & & \\
\hline \multirow[t]{2}{*}{ TLE6 } & XM_004009373 & F: 5' TACCTGCGCACCTGCCTGCT 3' & $58^{\circ} \mathrm{C}$ & 195 \\
\hline & & R: 5' ATTGGTGAAGCCAGCAAAAG 3' & & \\
\hline \multirow[t]{2}{*}{ ACTB } & NM_001009784 & F: 5' TTCCTGGGTATGGATCCTG 3' & $60^{\circ} \mathrm{C}$ & 162 \\
\hline & & R: 5' GGTGATCTCCTTCTGCATCC 3' & & \\
\hline \multirow[t]{2}{*}{ luciferase } & AF093685 & F: 5' GCTGGGCGTTAATCAGAGAG 3' & $58^{\circ} \mathrm{C}$ & 151 \\
\hline & & R: 5' GTGTTCGTCTTCGTCCCAGT 3' & & \\
\hline
\end{tabular}


5 mM DTT, 1 mM dNTPs, $2.5 \mu \mathrm{M}$ Random Hexamer primers, $0.05 \mu \mathrm{g}$ oligo $(\mathrm{dT})_{18}$ primers, $20 \mathrm{U}$ of RNase $\mathrm{OUT}^{\mathrm{TM}}$ and $100 \mathrm{U}$ of SuperScript ${ }^{\mathrm{TM}}$ III RT (all provided by Invitrogen Corporation, Carlsbad, CA). Negative control reactions (without the enzyme) were carried out to confirm the absence of genomic DNA contamination. The reaction tubes were incubated at $25^{\circ} \mathrm{C}$ for $10 \mathrm{~min}$, at $42^{\circ} \mathrm{C}$ for $1 \mathrm{~h}$ and finally at $70^{\circ} \mathrm{C}$ for $15 \mathrm{~min}$ to inactivate the reaction.

\section{Semi-quantitative PCR to analyse the transcript tissue distribution}

Semi-quantitative PCR experiments were carried out to assess the expression of the four genes in the different somatic tissues. First-strand cDNA ( 50 ng RNA) was used as a template for PCR amplification using genespecific primers [see Table 1 - primer sequence, annealing temperature (Ta) and length of amplification products]. The PCR consisted in $5 \mathrm{~min}$ at $95^{\circ} \mathrm{C}$, followed by 35 cycles of $94^{\circ} \mathrm{C}$ for $30 \mathrm{sec}$, Ta for $45 \mathrm{sec}$ and $72^{\circ} \mathrm{C}$ for $30 \mathrm{sec}$, and a final extension at $72^{\circ} \mathrm{C}$ for $10 \mathrm{~min}$. Ovine actin $\mathrm{B}(A C T B)$ gene was used as a positive control. The PCR products were evaluated by gel electrophoresis on a $2 \%$ agarose gel stained with Sybr Safe (Invitrogen) and visualised by exposure to blue light. The approximate size of the amplicons was estimated by comparison with the marker TrackIt $\varphi$ X174RF DNA/HaeIII.

\section{Cloning of ovine OOEP CDNA by PCR and RACE}

Rapid Amplification of cDNA Ends (RACE) was performed to isolate the OOEP full length transcript, using the primer SMART (CACACACAATTAACCCTCACTAAA GG) and an oligo dT primer modified for retro transcription (CCTCTCTATGGGCAGTCGGTGATCCTCAGC $(\mathrm{T})_{21}$. The product of the reverse-transcription was used as template for the following amplifications: to isolate the 5' region, the primers Fsmart (CACACACAATTAACCC TCACTAAAGG) and Rgsp3OOEP (GAGAAGCAAAT ATCCTTAAATCTCTGCCT) were used, while the primers OOEPforB (CTGTTGCATGAATGTTGTCG) and Roligo CODA (CTCTATGGGCAGTCGGTGA) were employed to isolate the 3 ' region.

Initially, the primers were designed based on conserved regions of bovine (NM_001077869), human (NM_001080507) and mouse (NM_026480) sequences, since the predicted ovine sequence (XM_004011571,) currently found in NCBI website, was not available when the analysis started.

TA Cloning kit (Invitrogen Corporation) was used to clone the fragments into the vector pCR2.1, using the chemocompetent cells TOP10. Several clones containing the fragments were sequenced.

The RACE was performed on total RNA isolated from prepubertal ovaries by the MICROCRIBI service at the Università degli Studi di Padova, Italy.

\section{Statistical analysis}

Data were analysed with MINITAB Release 12.1 software package (Minitab Inc., State College, PA, USA). After testing for normality and equal variance using the KolmogorovSmirnov and Levene tests, respectively, transcript data were analysed with analysis of variance (ANOVA). Student t-test was conducted to evaluate differences between the expression levels of adult (Ad) vs prepubertal (Pr) oocytes and embryos (within each stage separately). ANOVA was conducted to evaluate differences between different stages of development in each class of embryos (adult and prepubertal separately).

Differences were considered significant when $\mathrm{P}<0.05$.

\section{Results}

RNA in oocytes and pre-implantation embryos

RNA samples isolated from pools of 10 oocytes/embryos were analysed with Agilent 2100 Bioanalyzer (Agilent Technologies) with an RNA 6000 Pico kit (Agilent Technologies), specifically designed for analysis of low concentrated RNA samples (analysis range of total RNA: 50-5000 pg/ $\mu \mathrm{l}$ ). Results are described in Table 2. RNA samples isolated from 4-, 8- and 16- cell stage embryos are not included because below the lower limit of analysis $(<50 \mathrm{pg} / \mu \mathrm{l})$.

The quantification of the exogenous luciferase mRNA evidenced an RNA recovery rate of $52 \pm 5 \%$ (Mean \pm SD).

\section{cDNA cloning of ovine OOEP}

The full-length cDNA of OOEP was cloned by RACE technique in two fragments: the $5^{\prime}$ and the $3^{\prime}$. The amplification of the clones containing the $5^{\prime}$ fragment returned two products of different length (541 and 722 bps), while the amplification of the clones containing the 3 'fragment returned one product of 227 bps. In summary, two transcript variants were isolated: one of 679 bps (OOEP1) and one of 860 bps (OOEP2) (Figure 1). The sequences were submitted to GenBank (http://www.ncbi.nlm.nih.gov/genbank/; accession numbers: KF218578 for OOEP1 and KF741040 for OOEP2).

The alignment of the cDNA sequence with genomic DNA showed that OOEP1 consists in 3 exons of 203, 181 and 295 bps, spaced by two introns of 141 and 338 bps, while OOEP2 is composed by 3 exons of 113 , 181 and 566 bps, spaced by two introns of 232 and 68 bps (Figure 1).

BLAST analysis of OOEP1 cDNA confirmed the homology with the orthologous genes present in public databases: ovine sequence shares $95 \%$ identity with the bovine (NM_001077869.2; query cover 96\%), 81\% with the porcine (NM_001198917.1; query cover 56\%), 74\% with human (NM_001080507.2; query cover 79\%) and $72 \%$ with the murine (NM_174877; query cover 27\%) sequences. 
Table 2 Total RNA content of ovine Ad and Pr oocytes and embryos

\begin{tabular}{llllll}
\hline Stage & Mean concentration $(\mathbf{p g} / \mu \mathrm{l})$ & Mean SE $(\mathbf{p g} / \mu \mathrm{l})$ & Mean RIN value & $\begin{array}{l}\text { Isolated RNA (pg) per } \\
\text { oocyte or embryo** }\end{array}$ & $\begin{array}{l}\text { Estimated RNA (pg) per } \\
\text { oocyte or embryo** }\end{array}$ \\
\hline GV Ad & 314 & 41.6 & 8.3 & 471 & 942 \\
GV Pr & 170 & 61 & 5.9 & 253 & 538 \\
MII Ad & 95 & 53 & 6.7 & 142 & 285 \\
MII Pr & 80 & 22 & 5 & 119 & 238 \\
$\mathbf{2}$ cell Ad & 58 & 6 & 3.5 & 86 & 185 \\
$\mathbf{2}$ cell Pr & 80 & 14 & 4.4 & 120 & 240 \\
\hline
\end{tabular}

RNA samples isolated from pools of 10 oocytes/embryos were analysed with Agilent 2100 Bioanalyzer (Agilent Technologies) with an RNA 6000 Pico kit (Agilent Technologies), specifically designed for analysis of low concentrated RNA samples (analysis range of total RNA: 50-5000 pg/ $\mu$ l). RNA samples isolated from 4- 8- and 16- cell stage embryos are not included because below the lower limit of analysis $(<50 \mathrm{pg} / \mathrm{\mu l})$.

*Mean quantity of total RNA isolated per oocyte or embryo.

**Estimated RNA per oocyte or embryo, taking into account the RNA loss during RNA isolation, as resulted from analysis of the exogenous luciferase mRNA.

According to in silico translation, OOEP1 encodes a protein of 140 amino acids, and is homologues to the predicted mRNA sequence available in NCBI website (GenBank accession number XM_004011571).

BLAST analysis with homologous proteins showed that ovine sequence shares $95 \%$ identity with the bovine (NP_001071337.1; query cover 100\%), 67\% with the porcine (NP_001185846; query cover 100\%), 64\% with human (NP_001073976; query cover $100 \%$ ) and $45 \%$ with the murine (NP_080756; query cover 92\%) sequences (Figure 2).

In OOEP2 case, it was not possible to identify by in silico translation and BLAST analysis any product homologous to the sequences currently available in public databases.

\section{Expression of ovine NLRP5, KHDC3, TLE6 and OOEP in} oocytes and early embryos deriving from adult and prepubertal donors

The existence of KHDC3, TLE6 and OOEP mRNAs in sheep was confirmed.

The sequence of KHDC3 and TLE6 fragments is shown in Additional file 1, together with the homology with other mammalian species (Figure 3). The analysed sequence within the KHDC3 gene (150 bps) shares $97 \%$ homology with the bovine (XM_002690018.2), 86\% with the swine
(XM_003480279.1) and 82\% with human (NM_001017361.2) sequences. The analysed sequence within TLE6 gene (195 bps) shares 98\% homology with the bovine (XM_005209025.1), 89\% with porcine (XM_003354000.2), 81\% with the human (XM_005259645.1) and 78\% with murine (NM_053254.2) sequences.

Real time PCR analysis confirmed that NLRP5, KHDC3, TLE6, OOEP1 and OOEP2 are expressed in ovine oocytes (GV and MII stage) and in vitro produced early embryos (2-cell, 4-cell, 8-cell, 16-cell stage) derived from adult and prepubertal oocyte donors.

The expression of all analysed mRNAs appear to be maximal at the GV stage and to decrease during embryo preimplantation development (Figure 4). No transcript was detected at the blastocyst stage (Figure 5).

In oocytes and embryos derived from adult animals, all transcripts show a significant decrease in abundance between GV and MII (except for TLE6), between MII and $2 \mathrm{C}$ embryos and between $8 \mathrm{C}$ and $16 \mathrm{C}$ embryos (except for OOEP2). In oocytes and embryos derived from $\mathrm{Pr}$, the decreases are less sharp and involve different stages of development compared to Ad: i.e. NLRP5 abundance is stable during Pr oocyte maturation, conversely to what observed in $\mathrm{Ad}$, but shows a decrease between $4 \mathrm{C}$ and $8 \mathrm{C}$ Pr embryos, which does not occur in Ad. Similar peculiarities may be observed in KHDC3,

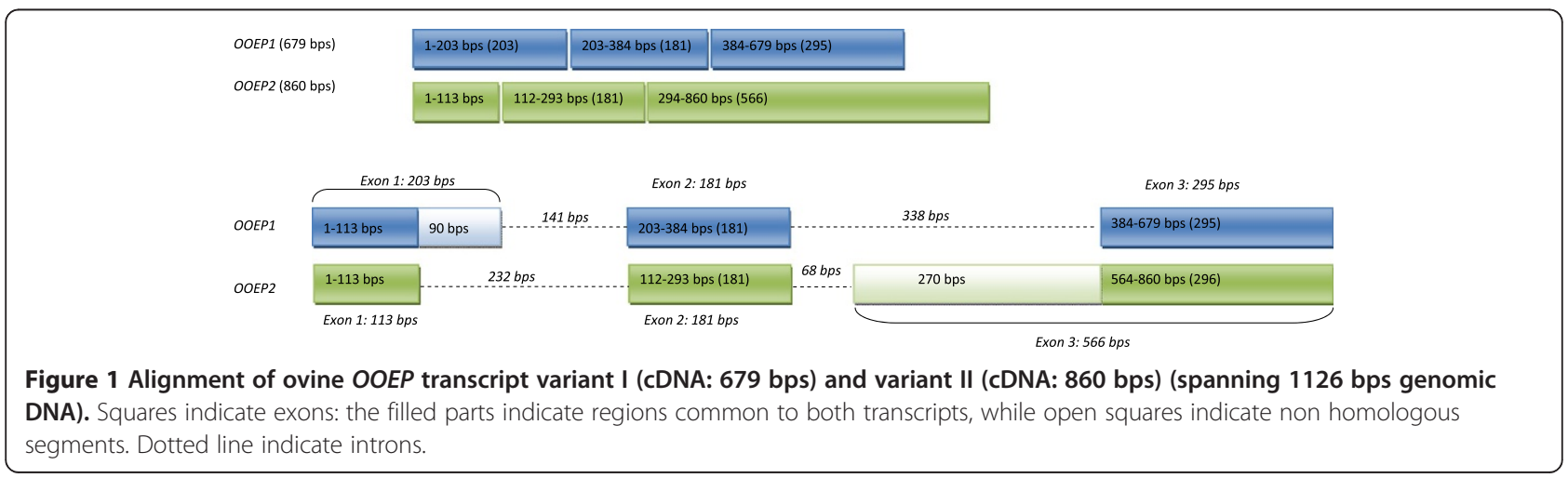


OOEP1, OOEP2 and TLE6 expression patterns in $\mathrm{Pr}$ (Figure 4). The pair-wise comparison between the expression patterns of Ad vs Pr groups (within each stage separately) reveals similar abundance for all five transcripts in GV and MII oocytes, with the exception of the lower KHDC3 levels in immaturePr oocytes. Conversely, all analysed mRNAs show significant differences around the 2 and 4 cell stage, with a higher abundance in the Prgroup (Figure 4).

OOEP1, OOEP2, TLE6, NLRP5 and KHDC3 tissue distribution Semi-quantitative analysis of NLRP5, KHDC3, TLE6, OOEP1 and OOEP2 expression in somatic tissues was carried out by PCR. NLRP5 and TLE6 are expressed only in ovaries, KHDC3 in ovaries, faintly in testis and cerebellum. OOEP1 was found in ovaries and testis, while $O O E P 2$ in ovaries, testis and cerebellum. No transcripts were detected in the other tissues (Figure 5).

\section{Discussion}

This is the first study that analyses the expression patterns of the SCMC components in a large mammalian species and associates the observed patterns to the developmental potential of the oocyte.

The existence of TLE6, KHDC3 and OOEP transcripts in sheep was assessed, and their expression in oocytes,
IVP pre-implantation embryos and somatic tissues was characterized, together with the expression of NLRP5, whose existence in sheep we had previously reported [24].

A model of differential competence consisting of oocytes derived from adult (Ad) or prepubertal (Pr) donors was used to analyse the expression of SCMC four components in relation to the oocyte developmental ability. Finally, the full length cDNA of OOEP was determined by Rapid Amplification of cDNA Ends (RACE).

In mouse, the abundance of the SCMC component mRNAs is maximal in in vivo derived, fully grown oocytes, abruptly decreases during ovulation and disappears by the 2-cell stage [1]. In our observations in sheep, expression of the SCMC components appeared to be maximal in GV oocytes and then to tail off during in vitro oocyte maturation and early embryo development. The transcripts persist in pre-implantation embryos up to the 8-16 cell stage and are not detectable at the blastocyst stage. In the Ad group, significant decreases in abundance are observed during maturation (except TLE6), between MII oocytes and 2C stage, and between 8 - and 16 cell stage (Figure 4). The differences in expression observed between mouse [1] and sheep are in accordance with the different time in embryonic genome activation (EGA) in the two species. In sheep, the major activation of the embryonic genome takes place 


A KHDC3
sheep
cow
human
pig
sheep
cow
human
pig
sheep
cow
human
pig

CAGACCCTGCTTCACGTTCATCAGTGGGACCCGAACGGCGAGGCTGAAATCTTGATATTT CAGACCCTGCTTCACGTTCATCAGTGGGATCCGGACGGCGAGGCTGAAATCTTGATATTT ------TGATTCACGTGAATCGATTGGACCCTAACGGCGAGGCTGAGATCTTGGTATTT CAGACACTGCTTCACATTAGTCAGTGGGACCCGGATGGCGAGGCTGAGATCCTGATATTT GGCCGGCCTTATTACCAGCAGGATGTATCCAAGATGATCATGAACTTGGCTAACTATCAC GGCCGGCCTTATTACCAGCAGGATGTATCCAAGATGATCATGAACTTGGCTGACTATCAC GGGAGGCCTTCTTACCAGGAGGACACAATCAAGATGATCATGAACCTGGCTGACTATCAC GGACGGCCTTATTACCAGATGGATGTATCCAAGATGATCATGAACTTGGCCGAGTACCAT

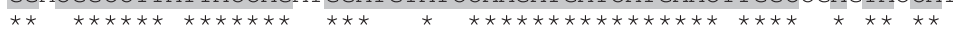
CGTCAGCTCCGGGCGCGAAGCTCTGAGAAG CGTCAACTCCGGGCGCGAAGCTCTGAGAAG CGCCAGCTCCAGGCGAAAGGCTC-----CGCCAACTCCGGGCGCAAA----------

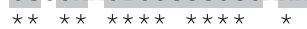

B TLE6
sheep
cow
pig
human
mouse
sheep
cow
pig
human
mouse
sheep
cow
pig
human
mouse
sheep
cow
pig
human
mouse

Figure 3 Fragments of ovine KHDC3L/FILIA and TLE6 CDNA sequences and homology with orthologous genes. (A) The analysed sequence within the KHDC3L gene (150 bps) shares 97\% homology with the bovine (XM_002690018.2), 86\% with the swine (XM_003480279.1) and 82\% with human (NM_001017361.2) sequences. (B) The analysed sequence within TLE6 gene (195 bps) shares 98\% homology with the bovine (XM_005209025.1), 89\% with porcine (XM_003354000.2), 81\% with the human (XM_005259645.1) and 78\% with murine (NM_053254.2) sequences. Homologous sequences are highlighted in grey.

later as compared to rodents (e.g. 8-16-cell stage vs. 1-2cell stage). The spreading of EGA over 3 to 4 cell cycles makes the ovine species an interesting model for studying the transcriptome because it allows a deep analysis of the progressive phases leading to the major wave of transcriptional activation. In fact, while in mouse a single major decrease in SCMC transcript abundance is abruptly observed during ovulation in vivo $[1,33]$, the patterns of expression in sheep highlight three different significant reductions in abundance (during maturation, around fertilization and between 8- and 16 cell stage), suggesting the need for the complex in three different moment of pre-implantation embryo development progression (Figure 4).

We have analysed the expression patterns of the SCMC in a model of differential developmental competence, in order to verify a potential link between the
mRNA abundance and the quality of the gamete. The model consists in ovine oocytes deriving from adult versus prepubertal donors; the oocytes derived from prepubertal animals can be fertilized, develop and give rise to a live offspring, however they show significanty lower developmental competence compared to oocytes derived from adult donors [34-36]. Both cytoplasmic and nuclear maturation of the oocyte are essential for the formation of an egg having the capacity for fertilization and development to live offspring [37]. Nuclear maturation encompasses the processes reversing meiotic arrest at prophase I and driving the progression of meiosis to metaphase II. Cytoplasmic maturation refers to the processes that prepare the egg for activation and preimplantation development [37]. The reduced developmental ability shown by Pr oocytes indicates that they are competent to undergo nuclear maturation, but contain a 

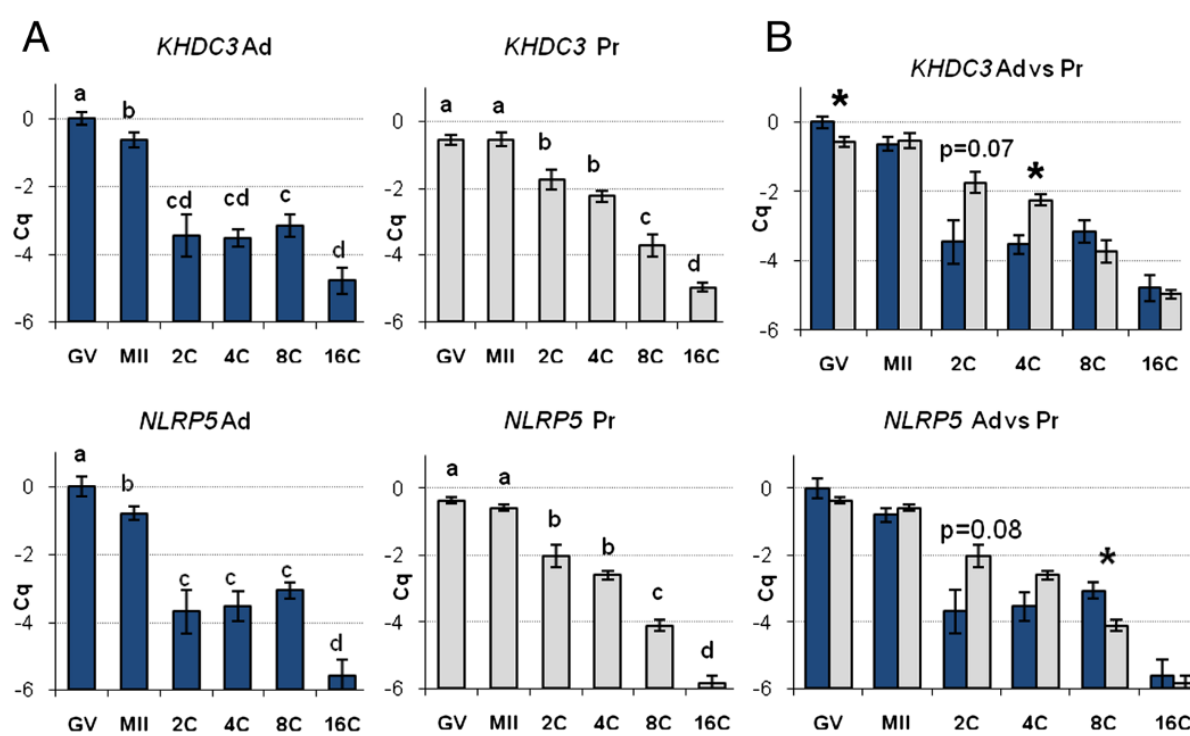

NLRP5 Pr

NLRP5 Advs Pr
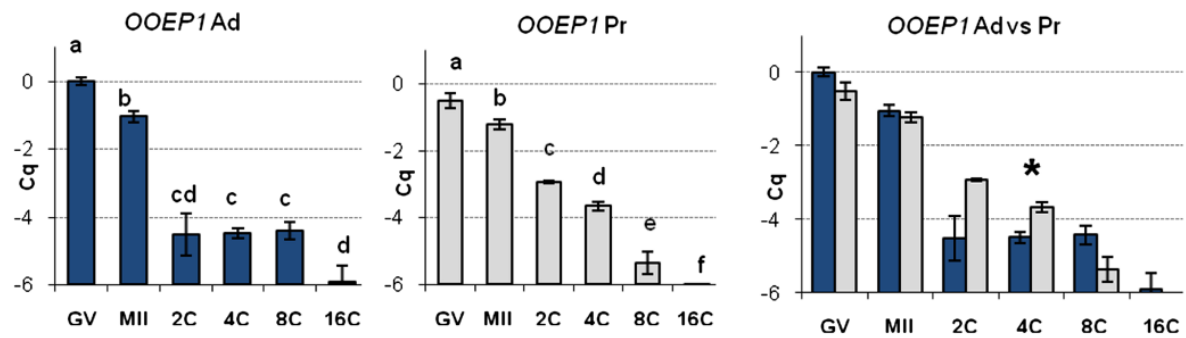

OOEP2Ad

OOEP2Pr
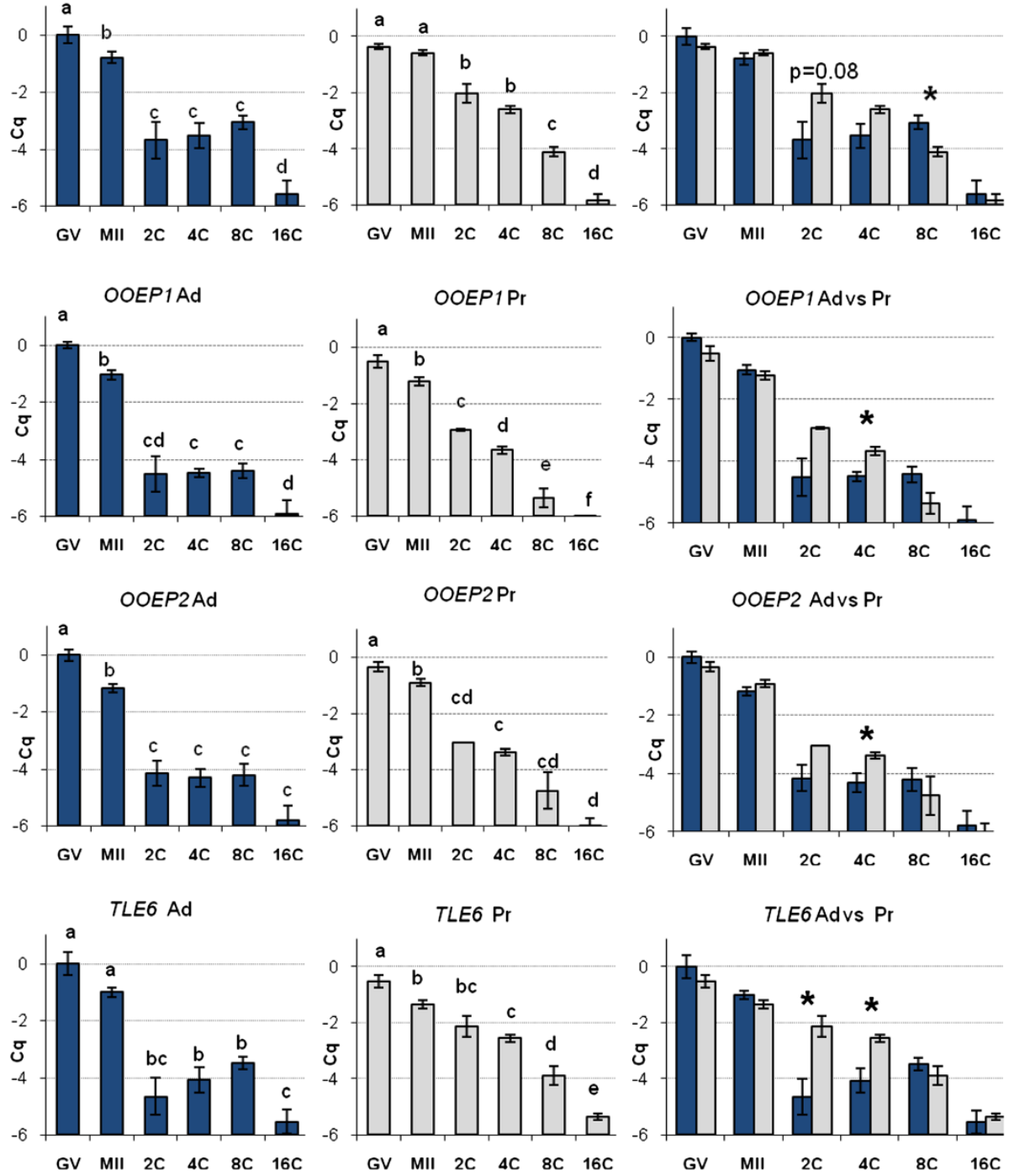

Figure 4 Relative expression of KHDC3/FILIA, NLRP5/MATER, OOEP1, OOEP2 and TLE6 in ovine immature (GV) and IVM MII oocytes (MII), in IVMFC two- (2C), four- (4C), eight- (8C), and 16-cell (16C) embryos derived from adult (Ad) or prepubertal (Pr) donors. Relative abundance values are expressed as $\Delta \mathrm{Cq}$ and show the mean value \pm s.e.m. of five (GV and MII) and three (2C, 4C, $8 \mathrm{C}$ and $16 \mathrm{C})$ replicates for each stage (each replicate $=$ pool of 10 oocytes/embryos). A. Different letters indicate a significant difference in relative mRNA abundance $(P<0.05)$ among the developmental stages. $\mathbf{B} .{ }^{*}$ indicates a significant difference in relative mRNA abundance $(P<0.05)$ in pairwise comparisons of oocytes/embryos at the same developmental stage derived from adult or prepubertal donors (Ad vs Pr). 


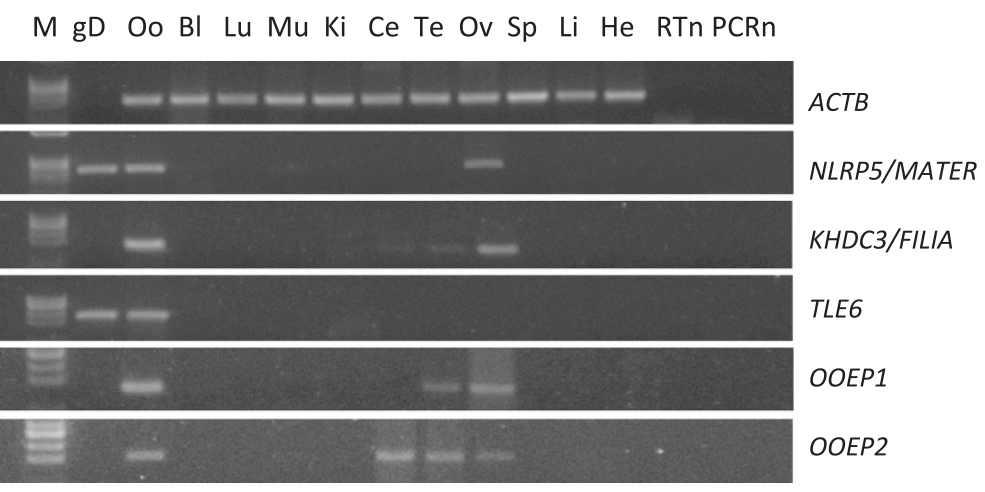

Figure 5 Tissue-specific expression of NLRP5, KHDC3, TLE6, OOEP1 and OOEP2, determined by total RNA reverse transcription and gene specific PCR. Actin B was analysed to control RNA integrity. $M=$ marker Tracklt $\varphi$ X174RF DNA/Haelll, Lane $1=$ genomic DNA; CDNA isolated from oocytes (Oo), blastocysts (Bl), lung (Lu), muscle (Mu), kidney (Ki), cerebellum (Ce), testis (Te) ovary (Ov), spleen (Sp), liver (Li) and heart (He) tissues. RTn = negative control, PCRn $=$ PCR negative control.

subset of molecules sufficient to support development only to some extent [38]. Therefore, Ad and Pr represent gametes of high versus low developmental competence, respectively, and constitute an ideal model for studying the relationship between cytoplasmic and nuclear competence of the oocyte. Interestingly, the expression analysis of the SCMC components in Ad vs Pr model consistently highlighted significant differences around the two-four cell stage of embryo development, with higher abundance in the Pr group (Figure 4). Although the exact function of the SCMC is yet to be clarified, the persistence of the transcripts until the $8-16$ cell stage presumes the need of the complex around oocyte to embryo transition and possibly beyond. The observation of similar levels of mRNAs in the Ad and $\operatorname{Pr}$ oocytes together with a higher abundance in the $\operatorname{Pr} 2 \mathrm{C}-4 \mathrm{C}$ embryos suggests a delay in the use of the transcripts by the Prembryos. The decrease in abundance observed in Ad embryos may be due to translation of the transcripts, in case more SCMC is needed, or to their degradation, if synthesis of the complex is no longer necessary. In $\mathrm{Pr}$, however, we observed a delay in the decrease of SCMC component transcripts during early embryo development, just before major genome activation of the nascent embryo. Whether the delay in the $\mathrm{Pr}$ embryos causes a shortage of SCMC or a surplus of transcripts, this may be detrimental for the progression of embryo development. The regulation of maternal transcript degradation is indeed as important as the accumulation of these molecules during oocyte growth, and the disruption of any of these mechanisms may severely impair the oocyte developmental competence [39]. Further analysis at protein level will clarify whether the SCMC protein content in oocytes and embryos reflects the observed transcriptional picture.

OOEP/FLOPED and KHDC3/FILIA belong to a family of genes with several members, located in a single syntenic region, that encode structurally related proteins with an atypical RNA-binding $\mathrm{N}$-terminal $\mathrm{KH}$ domain, named FILIA N Like, and are specifically expressed in oocytes and/or embryonic stem cells [27]. Compared to other canonical $\mathrm{KH}$ domains, a conserved N-terminal extension is identified prior to the $\mathrm{KH}$ domain in these proteins, although their function remains unknown. Interestingly, they are absent from fish, bird, and marsupial genomes and thus seem to have first appeared in eutherian mammals, in which they have evolved rapidly.

Two different research groups independently identified murine Ooep/Floped as a maternal effect gene, and part of the SCMC $[1,3]$. Maternally derived OOEP protein was seen to be essential for normal first cleavage and subsequent cell divisions: Ooep-null female mice are completely infertile because of a developmental impairment of the preimplantation embryos, that show slower cleavage and asymmetric blastomeres at 2 cell stage and never progress beyond [3]. These results indicate that OOEP protein has an important function around the zygotic stage, when mouse EGA occurs. In sheep, this corresponds to the 4-8 cell stage; as a consequence, the alteration in $O O E P$ transcript abundance we observed in ovine embryos at the 2-4 cell stage would likely affect proper development.

We determined the sequence of the full-length $O O E P$ cDNA from ovine ovary using rapid amplification of CDNA ends (RACE) and found two transcript variants of different length (679 and $860 \mathrm{bps).} \mathrm{The} \mathrm{shorter} \mathrm{variant,}$ hereafter referred to as OOEP1 (GenBank accession number: KF218578), was seen to be identical to the predicted full-length cDNA present in the NCBI database, with accession number XM_004011571. According to in silico translation, OOEP1 encodes for a 140 amino acid peptide that contains the atypical FILIA N Like domain, shared by the members of the above mentioned, rapidly evolving family of oocyte specific genes [27]. In 
accordance, the homology of the ovine gene with other mammalian species ranges from $95 \%$ identity in a $96 \%$ query cover with Bos taurus, to the $72 \%$ of only $27 \%$ query cover with M. Musculus.

Conversely, the second variant (OOEP2; GenBank accession number KF741040) is not homologous to any EST found in the NCBI database, and its potential reading frame is not obvious. The same reading frame for the two variants would be suggested by the exon-intron structure of the two transcripts. As shown in Figure 1, the second exon is identical in two variants, while the first and the third ones differ. The two non-homologous segments of exon 1 and 3 are 90 and 270 bps long, respectively; they display the characteristics of "symmetrical introns" [40] because their length is an exact multiple of 3 , so they potentially do not shift the reading frame. Nevertheless, applying to OOEP2 the same reading frame as OOEP1, a premature termination codon (PTC) lying in exon 1 stops its translation after 36 amino acids. The expression analysis of OOEP during oocyte maturation and embryo development showed that both transcripts persist with similar decreasing abundance up to the 16 cell stage (Figure 4). However, in the hypothesis of the same reading frame as OOEP1, the presence of a PTC would prevent the second variant from being translated.

Alternative splicing is known to produce also splice forms that are not being translated into proteins, but rather play a regulatory role $[10,41]$. It was suggested that as much as $35 \%$ of human alternative isoforms contain PTCs [42]; this widespread "unproductive" alternative splicing implies an important regulatory role, probably a post-transcriptional control of distinct genes [42-44]. A number of these non-protein coding transcripts are clearly processed from pre-mRNAs, and their genomic structure encompasses an exon-intron organization [10]. In this scenario, a regulatory role, possibly gene-specific, may be hypothesized for OOEP2.

A picture similar to $O O E P$ transcription in sheep was observed for Khdc3/Filia in mouse oocytes and embryos: $K h d c 3$ is transcribed as two types of transcripts with respective lengths of $1.2 \mathrm{k}$ and $1.6 \mathrm{k}$ base pairs that co-exist in oocytes, but only the former transcript is translated into a functional protein with 346 residues [33].

The identification of the alternative noncoding OOEP gene transcript, OOEP2, in ovine oocytes adds sheep to the list of mammalian species with experimentally confirmed observation of aberrant splicing during oogenesis.

In mouse, maternal KHDC3 plays a role in maintaining euploidy in cleavage-stage embryogenesis by integrating proper spindle formation; Khdc3 knock out females are not completely sterile, but their early embryos exhibit significant delays in development in association with lagging chromosomes, micronuclei and aneuploidy [4]. KHDC3 was seen to form a stable dimer in solution and to bind polynucleotides and endogenous RNA in vitro [45]. The atypical $\mathrm{KH}$ domain in $K h d c 3$ and Ooep gene family binds RNA like other canonical $\mathrm{KH}$-domain proteins, but might have unique consequences that are restricted to oocytes and early embryonic development [45]. Due to their similar expression profiles and their versatile binding with RNA via $\mathrm{KH}$ domains, [45] speculated that KHDC3 and OOEP function, either as a homo-dimer or in a multiple$\mathrm{KH}$ manner together in the SCMC in vivo, in RNA degradation during oocyte maturation or early embryogenesis. Our analysis in sheep confirms a similar pattern of expression for the two genes in ovine oocytes and preimplantation embryos, and the presence of the atypical FILIA N Like domain in the protein deduced from the sequence of ovine OOEP1 transcript; as a consequence, a similar role may be hypothesized in the ovine species as well.

In human, controversial evidence exists on a potential association between mutations in KHDC3 and recurrent biparental complete hydatidiform mole, which is the only known pure maternal-effect recessive inherited disorder in humans that results in recurrent pregnancy losses [46]. Mutations in $K H D C 3$ were found in women with familial diploid biparental hydatidiform mole s from four families $[47,48]$ and in two unrelated women with diploid biparental hydatidiform mole $s$ but without familial hydatidiform mole s [49]. However, discordant evidence seems to exclude mutations in this gene as a cause of non-familial biparental moles [50] and androgenetic moles [51].

The analysis of the SCMC component expression in somatic tissues pointed out additional information on the differences and overlaps between sheep and mouse species. In mouse, all four genes are expressed predominantly in the ovary $[1,8,33]$. In sheep, all genes are expressed in ovaries as well, but not exclusively: KHDC3 mRNA was detected also in testis and cerebellum, albeit faintly, while $O O E P$ transcript variants interestingly display two different patterns: OOEP1 was found in ovaries and testis whereas OOEP2 is expressed also in cerebellum (Figure 5). No transcripts were detected in the other tissues. This is in accordance with the observation of NLRP5/MATER expression in mouse and swine $[8,25]$, while bovine NLRP5 was observed also in testis [52]. No information on the expression of TLE6, KHDC 3 and OOEP in somatic tissues of species other than mouse is available. Furthermore, while no SCMC transcripts were detected in ovine blastocysts, murine $K h d c 3$ is expressed also by the embryo at the morula and blastocyst stages [33].

The expression of a MEG in nervous tissue has been previously reported in the case of Fmn2, a MEG expressed in the developing mammalian oocyte and required for DNA-spindle positioning during meiosis I [53]. The Fmn2 
genes in mouse and humans share conservation of sequence and genomic location, and were seen to be expressed throughout the brain and spinal cord [54].

\section{Conclusions}

In summary, this work describes for the first time the expression of the SCMC components in oocytes and in vitro produced preimplantation embryos in sheep. It reports the association between the patterns of expression in early embryos and the oocyte developmental potential in terms of delayed degradation of maternal NLRP5, KHDC3, OOEP and TLE6 transcripts in incompetent oocytes.

By reporting the alternative noncoding OOEP gene transcript, $O O E P 2$, it adds sheep to the list of mammalian species with experimentally confirmed observation of aberrant splicing during oogenesis.

The analysis of SCMC component expression patterns in a large mammalian species highlighted species-specific features that advance our understanding on the molecular differences underlying cytoplasmic vs nuclear maturation of the oocytes, and subsequent early embryonic development in mammals. Further analysis at protein level will clarify whether the observed transcriptional picture reflects the SCMC protein content in oocytes and embryos.

The comprehension of dissimilarities and overlaps in transcriptome composition between model organisms provides valuable information on genes that may play important regulatory roles in fertility in nonmurine models, including the human.

\section{Additional file}

Additional file 1: Fragments of ovine KHDC3/FILIA and TLE6 CDNA sequences. (a) Analysed sequence within the KHDC3 gene (150 bps). (b) Analysed sequence within TLE6 gene (195 bps).

\section{Competing interests}

The authors declare that they have no competing interests.

\section{Authors' contributions}

DB conceived the study, coordinated molecular biology experiments, analysed the data and wrote the manuscript; LM, LF and MF participated in molecular biology experiments and collection of samples; OM, FA and LB performed cell biology experiments; SL participated in design of the study and preparation of the manuscript. All authors read and approved the final manuscript.

\section{Acknowledgements}

Authors would like to thank dr. Cristina Fraumene for excellent assistance with Agilent 2100 Bioanalyzer analysis.

DB is the recipient of an RTD contract at the University of Sassari, Italy, for the project "Embryo mortality in the ovine species: identification of the factors responsible for pregnancy failures" granted by "P.O.R. SARDEGNA F.S.E. 2007-2013 - Obiettivo competitività regionale e occupazione, Asse IV Capitale umano, Linea di Attività I.3.1".

\section{Funding}

This work was supported by Regioni Sardegna e Lombardia [grant number 26096200, project "Ex ovo omnia"] and by Ministero dell'Istruzione, dell'Università e della Ricerca, PRIN 2009 [grant number 2009JE3CHM_002].
Received: 22 April 2014 Accepted: 11 November 2014

Published online: 25 November 2014

\section{References}

1. Li L, Baibakov B, Dean J: A subcortical maternal complex essential for preimplantation mouse embryogenesis. Dev Cell 2008, 15:416-425.

2. Tong ZB, Gold L, Pfeifer KE, Dorward H, Lee E, Bondy CA, Dean J, Nelson LM: Mater, a maternal effect gene required for early embryonic development in mice. Nat Genet 2000, 26:267-268.

3. Tashiro F, Kanai-Azuma M, Miyazaki S, Kato M, Tanaka T, Toyoda S, Yamato E, Kawakami H, Miyazaki T, Miyazaki J: Maternal-effect gene Ces5/Ooep/ Moep 19/Floped is essential for oocyte cytoplasmic lattice formation and embryonic development at the maternal-zygotic stage transition. Genes Cells 2010, 15:813-828.

4. Zheng P, Dean J: Role of Filia, a maternal effect gene, in maintaining euploidy during cleavage-stage mouse embryogenesis. Proc Natl Acad Sci U S A 2009, 106:7473-7478.

5. Dean J: Oocyte-specific genes regulate follicle formation, fertility and early mouse development. J Reprod Immunol 2002, 53:171-180.

6. Zheng P, Dean J: Oocyte-specific genes affect folliculogenesis, fertilization, and early development. Semin Reprod Med 2007, 25:243-251.

7. Wu X, Viveiros MM, Eppig JJ, Bai Y, Fitzpatrick SL, Matzuk MM: Zygote arrest 1 (Zar1) is a novel maternal-effect gene critical for the oocyte-to-embryo transition. Nat Genet 2003, 33:187-191.

8. Tong ZB, Nelson LM: A mouse gene encoding an oocyte antigen associated with autoimmune premature ovarian failure. Endocrinology 1999, 140:3720-3726.

9. Gilbert SF: Developmental biology. 6th edition. Sunderland MA: Sinauer Associates; 2000.

10. Evsikov AV, Graber JH, Brockman JM, Hampl A, Holbrook AE, Singh P, Eppig $\mathrm{JJ}$, Solter D, Knowles BB: Cracking the egg: molecular dynamics and evolutionary aspects of the transition from the fully grown oocyte to embryo. Genes Dev 2006, 20:2713-2727.

11. Vallee M, Robert C, Methot S, Palin MF, Sirard MA: Cross-species hybridizations on a multi-species CDNA microarray to identify evolutionarily conserved genes expressed in oocytes. BMC Genomics 2006, 7:113.

12. Vallee M, Aiba K, Piao Y, Palin MF, Ko MS, Sirard MA: Comparative analysis of oocyte transcript profiles reveals a high degree of conservation among species. Reproduction 2008, 135:439-448.

13. Telford NA, Watson AJ, Schultz GA: Transition from maternal to embryonic control in early mammalian development: a comparison of several species. Mol Reprod Dev 1999, 26:90-100.

14. Bettegowda A, Yao J, Sen A, Li Q, Lee KB, Kobayashi Y, Patel OV, Coussens PM, Ireland JJ, Smith GW: JY-1, an oocyte-specific gene, regulates granulosa cell function and early embryonic development in cattle. Proc Natl Acad Sci U S A 2007, 104:17602-17607.

15. Hanrahan JP, Gregan SM, Mulsant P, Mullen M, Davis GH, Powell R, Galloway SM: Mutations in the genes for oocyte-derived growth factors GDF9 and BMP15 are associated with both increased ovulation rate and sterility in Cambridge and Belclare sheep (Ovis aries). Biol Reprod 2004, 70:900-909.

16. Moore RK, Erickson GF, Shimasaki S: Are BMP-15 and GDF-9 primary determinants of ovulation quota in mammals? Trends Endocrinol Metab 2004, 15:356-361.

17. Galloway SM, MCNatty KP, Cambridge LM, Laitinen MP, Juengel JL, Jokiranta TS, McLaren RJ, Luiro K, Dodds KG, Montgomery GW, Beattie AE, Davis GH, Ritvos O: Mutations in an oocyte-derived growth factor gene (BMP15) cause increased ovulation rate and infertility in a dosage-sensitive manner. Nat Genet 2000, 25:279-283.

18. Galloway SM, Gregan SM, Wilson T, McNatty KP, Juengel JL, Ritvos O, Davis GH: Bmp15 mutations and ovarian function. Mol Cell Endocrinol 2002, 191:15-18.

19. Yan C, Wang P, DeMayo J, DeMayo FJ, Elvin JA, Carino C, Prasad SV, Skinner SS, Dunbar BS, Dube JL, Celeste AJ, Matzuk MM: Synergistic roles of bone morphogenetic protein 15 and growth differentiation factor 9 in ovarian function. Mol Endocrinol 2001, 15:854-866.

20. Dade S, Callebaut I, Mermillod P, Monget P: Identification of a new expanding family of genes characterized by atypical LRR domains: localization of a cluster preferentially expressed in oocyte. FEBS Lett 2003, 555:533-538.

21. Dade $\mathrm{S}$, Callebaut I, Paillisson A, Bontoux M, Dalbies-Tran R, Monget P: In silico identification and structural features of six new genes similar to 
MATER specifically expressed in the oocyte. Biochem Biophys Res Commun 2004, 324:547-553.

22. Paillisson A, Dade S, Callebaut I, Bontoux M, Dalbies-Tran R, Vaiman D, Monget $P$ : Identification, characterization and metagenome analysis of oocyte-specific genes organized in clusters in the mouse genome. BMC Genomics 2005, 6:76.

23. Swanson WJ, Vacquier VD: The rapid evolution of reproductive proteins. Nat Rev Genet 2002, 3:137-144.

24. Bebbere D, Bogliolo L, Ariu F, Fois S, Leoni GG, Tore S, Succu S, Berlinguer F, Naitana S, Ledda S: Expression pattern of zygote arrest 1 (ZAR1), maternal antigen that embryo requires (MATER), growth differentiation factor 9 (GDF9) and bone morphogenetic protein 15 (BMP15) genes in ovine oocytes and in vitro-produced preimplantation embryos. Reprod Fertil Dev 2008, 20:908-915.

25. Pisani LF, Ramelli P, Lazzari B, Braglia S, Ceciliani F, Mariani P: Characterization of maternal antigen that embryos require (MATER/ NLRP5) gene and protein in pig somatic tissues and germ cells. J Reprod Dev 2010, 56:41-48.

26. Zhang P, Dixon M, Zucchelli M, Hambiliki F, Levkov L, Hovatta O, Kere J: Expression analysis of the NLRP gene family suggests a role in human preimplantation development. PLoS One 2008, 3:e2755.

27. Pierre A, Gautier M, Callebaut I, Bontoux M, Jeanpierre E, Pontarotti P, Monget $P$ : Atypical structure and phylogenomic evolution of the new eutherian oocyte- and embryo-expressed KHDC1/DPPA5/ECAT1/OOEP gene family. Genomics 2007, 90:583-594.

28. Tervit HR, Whittingham DG, Rowson LE: Successful culture in vitro of sheep and cattle ova. J Reprod Fertil 1972, 30:493-497.

29. Walker SK, Hill JL, Kleemann DO, Nancarrow CD: Development of ovine embryos in synthetic oviductal fluid containing amino acids at oviductal fluid concentrations. Biol Reprod 1996, 55:703-708.

30. Bogliolo L, Ariu F, Leoni G, Uccheddu S, Bebbere D: High hydrostatic pressure treatment improves the quality of in vitro-produced ovine blastocysts. Reprod Fertil Dev 2011, 23:809-817.

31. Evsikov AV, Marín de Evsikova C: Gene expression during the oocyte-toembryo transition in mammals. Mol Reprod Dev 2009, 76:805-818.

32. Su YQ, Sugiura K, Woo Y, Wigglesworth K, Kamdar S, Affourtit J, Eppig JJ: Selective degradation of transcripts during meiotic maturation of mouse oocytes. Dev Biol 2007, 302:104-117.

33. Ohsugi M, Zheng P, Baibakov B, Li L, Dean J: Maternally derived FILIAMATER complex localizes asymmetrically in cleavage-stage mouse embryos. Development 2008, 135:259-269.

34. Armstrong DT, Holm P, Irvine B, Petersen BA, Stubbings RB, McLean D, Stevens G, Seamark RF: Pregnancies and live birth from in vitro fertilization of calf oocytes collected by laparoscopic follicular aspiration. Theriogenology 1992, 38:667-678.

35. Armstrong DT, Kotaras PJ, Earl CR: Advances in production of embryos in vitro from juvenile and prepubertal oocytes from the calf and lamb. Reprod Fertil Dev 1997, 9:333-339.

36. Ledda S, Bogliolo L, Leoni G, Naitana S: Production and lambing rate of blastocysts derived from in vitro matured oocytes after gonadotrophin treatment of prepubertal ewes. J Anim Sci 1999, 77:2234-2239.

37. Eppig JJ: Coordination of nuclear and cytoplasmic oocyte maturation in eutherian mammals. Reprod Fertil Dev 1996, 8:485-489.

38. Leoni GG, Bebbere D, Succu S, Berlinguer F, Mossa F, Galioto M, Bogliolo L, Ledda S, Naitana S: Relations between relative mRNA abundance and developmental competence of ovine oocytes. Mol Reprod Dev 2007, 74:249-257

39. Walser CB, Lipshitz HD: Transcript clearance during the maternal-tozygotic transition. Curr Opin Genet Dev 2011, 21:431-443.

40. Magen A, Ast G: The importance of being divisible by three in alternative splicing. Nucleic Acids Res 2005, 33:5574-5582.

41. Maquat LE: Nonsense-mediated mRNA decay: splicing, translation and mRNP dynamics. Nat Rev Mol Cell Biol 2004, 5:89-99.

42. Lewis BP, Green RE, Brenner SE: Evidence for the widespread coupling of alternative splicing and nonsense-mediated mRNA decay in humans. Proc Natl Acad Sci U S A 2003, 100:189-192.

43. Lareau LF, Green RE, Bhatnagar RS, Brenner SE: The evolving roles of alternative splicing. Curr Opin Struct Biol 2004, 14:273-282.

44. Hillman RT, Green RE, Brenner SE: An unappreciated role for RNA surveillance. Genome Biol 2004, 5:R8.
45. Wang J, Xu M, Zhu K, Li L, Liu X: The N-terminus of FILIA forms an atypical $\mathrm{KH}$ domain with a unique extension involved in interaction with RNA. PLoS One 2012, 7:e30209.

46. Van den Veyver IB, Al-Hussaini TK: Biparental hydatidiform moles: a maternal effect mutation affecting imprinting in the offspring. Hum Reprod Update 2006, 12:233-242.

47. Parry DA, Logan CV, Hayward BE, Shires M, Landolsi H, Diggle C, Carr I, Rittore C, Touitou I, Philibert L, Fisher RA, Fallahian M, Huntriss JD, Picton HM, Malik S, Taylor GR, Johnson CA, Bonthron DT, Sheridan EG: Mutations causing familial biparental hydatidiform mole implicate C6orf221 as a possible regulator of genomic imprinting in the human oocyte. Am $\mathrm{J}$ Hum Genet 2011, 89:451-458.

48. Fallahian M, Sebire NJ, Savage PM, Seckl MJ, Fisher RA: Mutations in NLRP7 and KHDC3L confer a complete hydatidiform mole phenotype on digynic triploid conceptions. Hum Mutat 2013, 34:301-308.

49. Reddy R, Akoury E, Phuong Nguyen NM, Abdul-Rahman OA, Dery C, Gupta N, Daley WP, Ao A, Landolsi H, Ann Fisher R, Touitou I, Slim R: Report of four new patients with protein-truncating mutations in C6orf221/KHDC3L and colocalization with NLRP7. Eur J Hum Genet 2013, 21:957-964.

50. Andreasen L, Bolund L, Niemann I, Hansen ES, Sunde L: Mosaic moles and non-familial biparental moles are not caused by mutations in NLRP7, NLRP2 or C6orf221. Mol Hum Reprod 2012, 18:593-598.

51. Manokhina I, Hanna CW, Stephenson MD, MCFadden DE, Robinson WP: Maternal NLRP7 and C6orf221 variants are not a common risk factor for androgenetic moles, triploidy and recurrent miscarriage. Mol Hum Reprod 2013, 19:539-544.

52. Pennetier $S$, Uzbekova $S$, Perreau $C$, Papillier $P$, Mermillod $P$, Dalbiès-Tran R: Spatio-temporal expression of the germ cell marker genes MATER, ZAR1, GDF9, BMP15, and VASA in adult bovine tissues, oocytes, and preimplantation embryos. Biol Reprod 2004, 71:1359-1366.

53. Leader B, Lim H, Carabatsos MJ, Harrington A, Ecsedy J, Pellman D, Maas R, Leder P: Formin-2, polyploidy, hypofertility and positioning of the meiotic spindle in mouse oocytes. Nat Cell Biol 2002, 4:921-928.

54. Leader B, Leder P: Formin-2, a novel formin homology protein of the cappuccino subfamily, is highly expressed in the developing and adult central nervous system. Mech Dev 2000, 93:221-231.

doi:10.1186/s12861-014-0040-y

Cite this article as: Bebbere et al: Expression of maternally derived KHDC3, NLRP5, OOEP and TLE6 is associated with oocyte developmental competence in the ovine species. BMC Developmental Biology 2014 14:40.

\section{Submit your next manuscript to BioMed Central and take full advantage of:}

- Convenient online submission

- Thorough peer review

- No space constraints or color figure charges

- Immediate publication on acceptance

- Inclusion in PubMed, CAS, Scopus and Google Scholar

- Research which is freely available for redistribution 